\title{
Simondon's Technical Culture and a Politics of Problems
}

\section{Stefano Daechsel}

\begin{abstract}
There is a timeliness to Gilbert Simondon's call in On the Mode of Existence of Technical Objects (1958) for a technical culture that fosters a "genuine awareness of technical realities." Writing in the context of mid-20 $0^{\text {th }}$ century France, Simondon worried about a lack of technological understanding and envisaged a technical culture in which technological education would be considered as essential as literacy to meaningful participation in society. Sixty years on, the need for widespread technological awareness is greater than ever. The aim of this article is to clarify and support this claim by examining it through the lens of a politics of problems that can be found in Deleuze's Difference and Repetition (1968).
\end{abstract}

Keywords: Simondon, Deleuze, technical culture, problems 
From artificial intelligence to climate change, the big challenges of the $21^{\text {st }}$ century will revolve around the evolution and distribution of technology. The problems we face locally, nationally and globally are increasingly defined by technical conditions that feel so complex and opaque to the average person that it can induce a sense of impotence or apathy. It is against this backdrop that the thought of the $20^{\text {th }}$ century philosopher Gilbert Simondon is belatedly garnering interest within and outside of his native France.

There are many reasons for this delayed interest in Simondon, not least his influence on better known French philosophers, such as Gilles Deleuze and Bernard Stiegler, but one of his most important and timely contributions is his call in On the Mode of Existence of Technical Objects $^{*}$ for a technical culture in which technical education would be considered as essential as literacy to meaningful participation in society. Sixty years on, with the spread of technology in all facets of human existence, his project has become a political necessity.

The overarching aim of this article is to bolster Simondon's call for a technical culture by situating it within what I call a politics of problems inspired by Deleuze's unique understanding of problems and summed up as a struggle to participate in the determination of social, political and economic problems. Although Deleuze himself only hints at a politics of problems ${ }^{\dagger}$ I propose that the concept is an important component of Deleuze's political thought that complements Simondon's ideas in On the Mode of Existence of Technical Objects.

To date, the literature on Deleuze and Simondon has largely dealt with the former's debt to the latter, particularly on the concept of individuation which plays an important role in both of their respective ontologies. ${ }^{\ddagger}$ While the exploration of

\footnotetext{
* Simondon's two primary works, L'individuation à la lumière des notions de forme et d'information [Individuation in Light of Notions of Form and Information] and Du mode d'existence des objets techniques [On the Mode of Existence of Technical Objects], were both submitted in 1958 as his primary thesis and complementary thesis for the doctorat d'Etat, but an English translation of On the Mode of Existence of Technical Objects was only published in 2017 and an English version of Individuation in Light of Notions of Form and Information has just been published in 2020.

${ }^{+}$To date, the literature on Deleuze's notion of problems in Difference and Repetition has yet to address the explicitly political implications of problems that Deleuze himself alludes to on several occasions. Instead, the focus has been on the "noetic aspects" (Bowden, "Anti-Positivist Conception of Problems," 56) of Deleuzian problems - how problems operate in the formation of thoughts and the thinking subject - or their philosophical lineage through thinkers such as Kant, Nietzsche, Bergson and Heidegger (Wasser, "How to Recognise Problems?"). Consequently, more work is needed to fully flesh out the notion of a Deleuzian politics of problems.

"See Andrew Illiadis, "A New Individuation: Deleuze's Simondon Connection," Media Tropes, 4 no.1 (2013), 83-100; Sean Bowden, "Gilles Deleuze, a Reader of Gilbert Simondon," in Gilbert Simondon: Being and Technology, eds. Arne De Boever, Alex Murray, Jon Roffe and Ashley Woodward, (Edinburgh: Edinburgh University Press, 2012), 135-153; Filippo Del Lucchese, ”Monstrous Individuations: Deleuze, Simondon, and Relational Ontology," Differences 20, no. 2-3, 179-193.
} 
the connections between their ontological frameworks is interesting and important, my focus here is to combine more overtly political elements of their philosophies in order to make a case for Simondon as a timely thinker that warrants our belated interest. ${ }^{*}$

\section{A Deleuzian Politics of Problems}

Although Difference and Repetition is first and foremost an exposition of Deleuze's ontology and his theory of transcendental empiricism, it also contains flashes of a political sensibility that is geared towards the formulation and solving of problems. Deleuze develops his theory of problems most notably in the third chapter of Difference and Repetition, 'The Image of Thought,' which reads as a scathing critique of Deleuze's philosophical enemies, especially Descartes and Hegel. He also admonishes a "grotesque image of culture" founded on an impoverished understanding of problems:
We are led to believe that problems are given ready-made, and that they disappear in the responses or the solution [...] According to this infantile prejudice, the master sets a problem, our task is to solve it, and the result is accredited true or false by a powerful authority. It is also a social prejudice with the visible interest of maintaining us in an infantile state, which calls upon us to solve problems that come from elsewhere, consoling or distracting us by telling us that we have won simply by being able to respond: the problem as obstacle and the respondent as Hercules. ${ }^{\ddagger}$

In this passage, Deleuze lays out a number of challenges to the conventional understanding of a problem. Consider a multiple-choice standardised test: The person sitting the test is confronted with a question and a list of potential answers of which one is the correct response. Everything is given (ready-made) and the sole task of the testee is to correctly identify the answer, i.e., the problem's solution. Once the solution is identified, there is nothing left to do but to move on to the next question. It is possible to extend this notion of the ready-made problem to other facets of everyday life, be it the choices between consumer products - choices that

\footnotetext{
* Several cases for the importance of Simondon's work have already been made convincingly, see Muriel Combes, Gilbert Simondon and the Philosophy of the Transindividual, trans. Thomas LaMarre (Cambridge: the MIT Press, 2013); Xavier Guchet, Pour un humanisme technologique (Paris: Presses Universitaires de France, 2010); Jean-Hugues Barthélémy, "Deux points d'actualité de Simondon," Revue philosophique de la France et de l'étranger, no.3 (2006), 299-310.

${ }^{\dagger}$ Gilles Deleuze, Difference and Repetition, trans. Paul Patton (London: Continuum, 1994), 158.

${ }^{*}$ Deleuze, Difference and Repetition, 158.
} 
we are led to believe are highly consequential (Pepsi or Coke?) - or deciding between political parties at the ballot box. In all these cases, the task is to choose among a given set of options.

Deleuze maintains that our societal fixation on finding the correct solutions to ready-made problems keeps us in a state of infantilisation because "the solution necessarily follows from the complete conditions under which the problem is determined as problem, from the means and the terms which are employed in order to pose it."* How a problem is formulated and framed determines which solutions are possible. For instance, when climate change is formulated as a problem of personal consumption, the proposed solutions are either to purchase products with smaller carbon footprints or to reduce one's consumption altogether. Under this formulation, the need for sustainable alternatives to fossil fuels as our primary source of energy is ignored, as are the collective efforts to accelerate a transition away from fossil fuels, solutions that only arise when the problem is formulated differently. Thus, "a problem always finds the solution it merits, according to the conditions which determine it as a problem." ${ }^{\prime}$

Granted, ready-made problems give us some agency - we still get to choose whether to buy organic or not - but they infantilise and distract us "from the most important task, that of determining problems and realising in them our power of creation and decision." " For Deleuze, this amounts to a form of social control, treating us "[a]s if we would not remain slaves so long as we do not control the problems themselves, so long as we do not possess a right to the problems, to a participation in and management of the problems." $\$$ Who participates in the formulation of problems, in their determination, is a fundamentally political question because it is in the determination of problems that solutions are given.

Thus, Deleuze offers an outline of what I would like to call a politics of problems, a politics centred around the struggle to participate in the determination of problems. Yet, the full significance of this concept is only made apparent once we consider Deleuze's unique understanding of problems and how they fit into his wider philosophical system.

\footnotetext{
* Deleuze, Difference and Repetition, 159.

${ }^{\dagger}$ Gilles Deleuze, The Logic of Sense, trans. Mark Lester (London: The Athlone Press, 1990), 54.

₹ Deleuze, Difference and Repetition, 268.

${ }^{\S}$ Deleuze, Difference and Repetition, 158.
} 


\section{Deleuzian Problems}

In 1966, Deleuze wrote a highly favourable review of Simondon's book L'individu et sa genèse physico-biologique [The Individual and its Physico-Biological Genesis], an abridged version of his 1958-thesis, L'individuation à la lumière des notions de forme et d'information. He especially commends Simondon's use of the category of problem:

This category of problem acquires in Simondon's thought tremendous importance insofar as the category is endowed with an objective sense: it no longer designates a provisional state of our knowledge, an undetermined subjective concept, but a moment of being, the first pre-individual moment. ${ }^{*}$

Deleuze would go on to reiterate this point two years later in Difference and Repetition, and again in The Logic of Sense where he writes:

We must [...] break with the long habit of thought which forces us to consider the problematic as a subjective category of our knowledge or as an empirical moment which would indicate only the imperfection of our method and the unhappy necessity for us not to know ahead of time - a necessity which would disappear as we acquire knowledge. ${ }^{\dagger}$

Deleuzian problems are not "provisional and contingent movements [undergone by a subject that are] destined to disappear in the formation of knowledge" ${ }^{\ddagger}$ but ontologically independent realities that are objective; their existence does not depend on "a thinking subject who exists in an independent and prior way," as the philosopher Sean Bowden explains. ${ }^{\S}$ That said, Aubrey Wasser rightly notes that Deleuze's problems are not recognisable in the same way as "objects of sense experience".** Contrary to the latter, "[p]roblems are not unified and independently existing entities that might be perceived, conceptualized or picked-out as such by true empirical propositions" ${ }^{+\dagger}$ Deleuze himself describes problems as "multiplicities." A multiplicity is not "a combination of the many and the one, but rather an organisation belonging to the many as such, which has no need

\footnotetext{
* Gilles Deleuze, Desert Islands and Other Texts 1953-1974, trans. Michael Taormina (New York: Semiotext(e), 2004), 88.

${ }^{\dagger}$ Deleuze, Logic of Sense, 54 .

${ }^{*}$ Deleuze, Difference and Repetition, 159.

§ Sean Bowden, "An Anti-Positivist Conception of Problems," Angelaki 23, no. 2 (2018), 56.

** Aubrey Wasser, "How Do We Recognise Problems?," Deleuze Studies 11, no.1 (2017).

+' Bowden, "Anti-Positivist Conception of Problems," 56.

\# Deleuze, Difference and Repetition, 163.
} 
whatsoever of unity in order to form a system." Understood as a multiplicity, a problem is a distinct system of "differential relations between genetic elements" ${ }^{\dagger}$ but it eludes a definitive determination or resolution. As a consequence, problems can be expressed in a number of solutions depending on which genetic elements are included in a particular determination. Problems are virtual, while their solutions are actual..$^{\ddagger}$

Concerning the concept of a politics of problems, two consequences of Deleuze's theory of problems are crucial to note. First, a problem is determined as it is solved and, second, a problem does not disappear once it is solved. The first consequence rejects the notion of ready-made problems while the second challenges the conventional understanding of a problem as a temporary obstacle that vanishes once it is overcome. By treating problems as virtual multiplicities, Deleuze gives them a certain ontological independence from their actual solutions because the virtual is not exhausted when it is actualised, but persists as a "reservoir" ${ }^{\text {of genetic elements }}$ that can be expressed in new actualisations, i.e., new solutions.

Thus, seemingly resolved problems could be solved differently. For example, the nation-state continues to be the dominant solution to the problem of political power - how it should be distributed and managed across the globe - but the problem itself never ceased to exist and other solutions are possible. Solving a problem differently entails reaching into its reservoir of genetic elements to find new determinations that structure the actualisation of new solutions.

In the conclusion of Difference and Repetition, Deleuze makes explicit the political ramifications of his theory of problems. Against the politics of negation suggested by the Hegelian dialectic - in which the contradictions between a thesis and its negation (antithesis) resolve themselves in a synthesis - Deleuze proposes an affirmative politics centred on the determination of problems:

History progresses not by negation and the negation of the negation, but by deciding problems and affirming difference. It is no less bloody and cruel as a

\footnotetext{
${ }^{*}$ Deleuze, Difference and Repetition, 182.

${ }^{\dagger}$ Deleuze, Difference and Repetition, 181.

* In Difference and Repetition, Deleuze proposes a tripartite ontology that partitions the real into three registers: the virtual, the intensive and the actual. For Deleuze, the "virtual is opposed not to the real but to the actual. The virtual is fully real in so far as it is virtual." Every being has a virtual dimension, an intensive dimension and an actual dimension, and all three dimensions are equally real. A problem is the virtual dimension of a being or object that structures its actualisation by intensive differences. The agents of actualisation are intensive, but the conditions that structure actualisation are virtual. For Deleuze, "[ $t]$ he reality of the virtual is structure," but a structure that is not immutable or rigidly deterministic.

${ }^{\S}$ Deleuze, Difference and Repetition, 246.
} 
result. Only the shadows of history live by negation: the good enter into it with all the power of a posited differential or a difference affirmed; they repel shadows and deny only as the consequence of a primary positivity and affirmation [...] This is why real revolutions have the atmosphere of fêtes. Contradiction is not the weapon of the proletariat but, rather, the manner in which the bourgeoisie defends and preserves itself, the shadow behind which it maintains its claim to decide what the problems are. Contradictions are not 'resolved', they are dissipated by capturing the problem of which they reflect only the shadow.*

Political action cannot be reduced to mere opposition to an existing solution or to how a problem is formulated; it must attempt to determine problems differently, affirm new solutions and formulate new problems altogether. In Difference and Repetition, an affirmative politics of problems replaces a negative politics of opposition and contradiction. ${ }^{\dagger}$

\section{Simondon, Technics and the Politics of Problems in the $21^{\text {st }}$ Century}

What then is the link between a politics centred on the formulation of problems and Simondon's call for a technical culture? In On the Mode of Existence of Technical Objects, Simondon argues for a new humanist project centred on expanding technical education because " $[t]$ he most powerful cause of alienation in the contemporary world resides in [a] misunderstanding of the machine, which is not an alienation caused by the machine, but by the non-knowledge of its nature and its essence." ${ }^{\ddagger}$ The aim of his project is to give people the ability to meaningfully engage with their contemporary technical reality and, in so doing, update our cultural understanding of technical objects. I maintain that this project has important implications for a politics of problems in the $21^{\text {st }}$ century.

\footnotetext{
${ }^{*}$ Deleuze, Difference and Repetition, 268.

${ }^{+}$Deleuze clearly considers Simondon an ally in his struggle against the Hegelian dialectic and its emphasis on negation. In his review, Deleuze writes that "in Simondon's dialectic, the problematic replaces the negative." Deleuze, Desert Islands, 88.

${ }^{*}$ Gilbert Simondon, On the Mode of Existence of Technical Objects, trans. Cecile Malaspina and John Rogove (Minneapolis: University of Minnesota Press, 2017), 16. It is important to stress that Simondon's humanism is unconventional in that it is not anthropocentric. His project consists not only in reducing alienation among humans but also, as the title suggests, in elevating the cultural standing of technical objects from mere instruments in the service of human goals to meaningful elements of existence.
} 
For Simondon, our cultural understanding of technics is outdated because it "relies on the experience of the man working with tools." Through this instrumentalist lens, technical objects are conceived as means to an end. However, this understanding ignores a series of historical changes in the relationship between humans and technical objects that started during the industrial revolution. Not only does industrialisation see the machine replace "man as tool bearer," ${ }^{\dagger}$ it creates vast networks of technical objects that are "beyond the forces of the individual." ${ }^{\ddagger}$ For Simondon, it is the networked, or reticular, nature of modern technics that forces us to reimagine technical objects as more than instruments or means to an end:

Indeed, the reticular structures of integrated technics are no longer mere means available for an action and abstractly transportable anywhere, utilizable at any moment; one changes tools and instruments, one can construct or repair a tool oneself, but one cannot change the network, one doesn't construct a network of one's own: one can only connect to a network, adapt to it, participate in it; the network dominates and frames [enserre] the action of the individual. ${ }^{\S}$

Instead of an ensemble of means, networked technical objects are "an ensemble of conditionings of action and of incitements to act." ${ }^{* *}$ As the philosopher Muriel Combes explains, Simondon's characterization of "technicity in terms of reticularity is what allows us to make a radical break with the description of technics based on the category of means, and in sum, to break with the schema of utility, which is suited only to the tool." ${ }^{\prime \dagger}$ Technical networks condition human action and thus require a new understanding of technics as a structuring force with social and political ramifications.

Today, it would seem that the existence and significance of technical networks has penetrated into our cultural understanding of technology. And yet, instrumentalist attitudes towards technical objects and networks persist, ${ }^{*}$ and the extent to which they condition human action is difficult to establish because of a persistent lack of technological education. From the perspective of a politics of

\footnotetext{
* Simondon, On the Mode of Existence of Technical Objects, 20.

' Simondon, On the Mode of Existence of Technical Objects, 78.

* Simondon, On the Mode of Existence of Technical Objects, 119.

\$ Simondon, On the Mode of Existence of Technical Objects, 229.

** Simondon, On the Mode of Existence of Technical Objects, 229.

${ }^{+}$Combes, Philosophy of the Transindividual, 67.

\# That Mark Zuckerberg and other public-facing employees regularly refer to Facebook as a 'tool' is a case in point of this persistent instrumentalist logic.
} 
problems, this partial awareness of our technological reality is consequential because it hinders our ability to properly formulate social, political and economic problems that invariably have technological conditions. The social theorist Conor Heaney notes that, for Simondon, every new technology is both "a relation to the milieu and a modification of it, with successive modifications transforming the milieu itself and therefore the conditions of action for those within it. A transformed milieu creates new problems, stimulating further modifications."*

Simondon frames this cascading effect of modification-problem-modification as an integral part of the genesis of technics, but the same logic can be expanded beyond the realm of technical invention. The solutions to technical problems become the conditions of bigger problems, especially in the era of concrete technical networks that permeate and condition all facets of human interaction.

In certain cases, the technological component of a problem is apparent: political disinformation on the internet, cybercrime and mass surveillance technologies, to name but a few. Still, other problems have more subtle technological dimensions that can easily be overlooked, such as income inequality or attention deficit disorders. Whether the technological components of a problem are obvious or not, we run the risk of misunderstanding or ignoring them. Consequently, problems are formulated poorly and the solutions they generate are inadequate to the challenges we face. The point is not that all problems and their solutions are strictly technological, but that the technological dimensions of our problems cannot be ignored if we are to determine them better.

Underpinning this troubling state of affairs is the simple fact that most people do not participate in the formulation and resolution of technological problems. Despite the sense that every generation is more technologically literate than its predecessor, there is a big difference between being able to use technology and being able to formulate technological problems. For Simondon, the problem isn't that people don't know how to use technical objects but that most of us tend to engage with machines solely as workers or consumers. Learning how to use a new device is, more often than not, a 'ready-made' problem where the solution is given and minimal effort is required, if not expected. Not only does this reinforce an instrumentalist understanding of technics, it leaves us incapable of changing the technical networks that condition our behaviour.

\footnotetext{
"Heaney, "The disparity between culture and technics," 197.
} 
Meanwhile, the task of formulating and resolving technological problems demands more technological understanding and more material resources than most people currently possess. The outcome has been a tech-sector increasingly dominated by a handful of mega-companies that wield an immense amount of influence on the formulation of technological problems. ${ }^{*}$ The ongoing development of artificial intelligence (AI) is but one extreme example of how the concentration of the power to formulate and resolve technological problems can have serious political and social ramifications. ${ }^{\dagger}$

For these reasons, there is an urgency to Simondon's call for a technical culture that would foster a "genuine awareness of technical realities" education and technical activity. Such an awareness of technics "possesses political and social value: it can give man the means for thinking his existence and situation according to the reality that surrounds him," a reality that is profoundly technological.

Not only would we acquire "the philosophical and notional awareness of technical reality"** as a reticular and conditioning force, but a technical culture would allow more people to actively participate in the formulation and resolution of technological problems. In so doing, they would come to realise that every technical object is a solution to a problem that could be solved differently because, as Deleuze shows us, a problem is never exhausted or extinguished in its solution. This realisation opens up new horizons of technological discovery that are not subservient to market or geopolitical forces and that no longer reduce technical objects to their utility.

Already, these alternative trajectories of technological experimentation can be found in phenomena like the movement for free and open source software and, more

\footnotetext{
* In her book, The Big Nine (2019), Amy Webb explains how the future of artificial intelligence (AI) is largely being shaped by nine tech giants: six American companies (Google, Amazon, Apple, IBM, Microsoft and Facebook) and three Chinese companies (Baidu, Alibaba and Tencent). Acting under the pressure of market and governmental forces, Webb argues that these companies have placed AI on a dangerous developmental track that could turn it into a fundamentally anti-democratic technology.

${ }^{+}$In her discussion of another important French thinker of technics, Bertrand Gille, Daniela Voss notes that "[i]nvention as an individual initiative becomes more and more impossible due to the amount of scientific knowledge and laboratory equipment required, and the rising costs of research." As a result, invention "has become institutionalised in official departments financed by state agencies (military, state universities, etc.) and large corporations (corporate research unites, laboratories, adjunct foundations at universities, etc.)." Access to these institutions is guarded and the post-secondary qualifications required to be admitted as a member are made scarce by some combination of financial cost and entrance requirements.

${ }^{*}$ Simondon, On the Mode of Existence of Technical Objects 19.

${ }^{\S}$ Simondon, On the Mode of Existence of Technical Objects, 20.

${ }^{* *}$ Simondon, On the Mode of Existence of Technical Objects, 235.
} 
recently, the maker movement, a global network of people who make their own electronics and share their designs and experiences online and in person. These movements encourage people to move beyond the role of consumer to become makers and hackers who engage in the activity of invention and, in so doing, learn to pose and solve technological problems. They also resonate with Simondon's project because they depart from the paradigm of work which treats technical objects as means of production for a definite task. Instead, the maker movement and the movement for free and open source software approach technical objects as open sites of intervention and learning and their creations are designed to facilitate further experimentation rather than conceal their internal mechanisms as is often the case with commercial products. ${ }^{*}$

A challenge, however, is that both movements have been vulnerable to industry capture and have had limited success in engaging people who do not already have a professional or educational background in computer science or design. Thus, the transition from a technologically illiterate culture to the technical culture that Simondon imagines will require more radical and structural changes to our socioeconomic order than can be achieved by makers and hackers alone. Indeed, without widespread technological education in schools and major changes to the way technology is regulated and developed, it is difficult to conceive of an inclusive and participatory technical culture that would enable more people to affect the trajectory of technology and engage in a politics of problems increasingly defined by technological conditions.

\footnotetext{
*I develop this point and the relationship between the maker movement and Simondonian thought in Stefano Mazzilli-Daechsel, "Simondon and the maker movement," Culture, Theory and Critique, vol. 60, no. 3-4 (2019).
} 


\section{References}

Bardin, Andrea. Epistemology and Political Philosophy in Gilbert Simondon: Individuation, Technics, Social Systems. London: Springer, 2015.

Barthélémy, Jean-Hugues. Deux points d'actualité de Simondon, Revue philosophique de la France et de l'étranger, no.3 (2006), 299-310.

Bowden, Sean. An Anti-Positivist Conception of Problems, Angelaki 23, no. 2 (2018), 56.

Bowden, Sean. Gilles Deleuze, a Reader of Gilbert Simondon, in Gilbert Simondon: Being and Technology, eds. Arne De Boever, Alex Murray, Jon Roffe and Ashley

Woodward, Edinburgh: Edinburgh University Press, 2012, 135-153

Combes, Muriel. Gilbert Simondon and the Philosophy of the Transindividual.

Translated by Thomas LaMarre. Cambridge: the MIT Press, 2013.

DeLanda, Manuel. Intensive Science and Virtual Philosophy. London: Continuum, 2002.

Deleuze, Gilles. Desert Islands and Other Texts 1953-1974. Translated by Michael Taormina. New York: Semiotext(e), 2004.

Deleuze, Gilles. Difference and Repetition. Translated by Paul Patton. London: Continuum, 1994.

Deleuze, Gilles. The Logic of Sense. Translated by Mark Lester. London: The Athlone Press, 1990.

Del Lucchese, Filippo. Monstrous Individuations: Deleuze, Simondon, and Relational Ontology, Differences 20, no. 2-3 (2009), 179-193.

Guchet, Xavier. Pour un humanisme technologique. Paris: Presses Universitaires de France, 2010.

Heaney, Conor. The disparity between culture and technics, Culture, Theory and Critique 60, no.3-4 (2019), 193-204.

Illiadis, Andrew. A New Individuation: Deleuze's Simondon Connection, Media Tropes, 4 no.1 (2013), 83-100.

Mazzilli-Daechsel, Stefano. Simondon and the maker movement, Culture Theory and Critique 60, no 3-4 (2019), 237-249.

Simondon, Gilbert. Individuation in Light of Notions of Form and Information. Translated by Taylor Adkins. Minneapolis: University of Minnesota Press, 2020.

Simondon, Gilbert. L'individuation à la lumière des notions de forme et d'information. Grenoble: Millon, 2017.

Simondon, Gilbert. On the Mode of Existence of Technical Objects. Translated by Cécile Malaspina and John Rogove. Minneapolis: University of Minnesota Press, 2017. 
Simondon, Gilbert. Sur la technique. Paris: Presses Universitaires de France, 2014.

Voss, Daniela. Invention and capture: a critique of Simondon, Culture, Theory and Critique 60, no 3-4 (2019), 279-299.

Wasser, Aubrey. How Do We Recognise Problems?, Deleuze Studies 11, no.1 (2017), 49 .

Webb, Amy. The Big Nine: How the Tech Titans and their Thinking Machines Could Warp Humanity. New York: Public Affairs, 2019. 